\title{
COMMENTARY
}

\section{Eubaric hyperoxia: controversies in the management of acute traumatic brain injury}

Pradeep K Narotam

See related research by Raj et al., http://ccforum.com/content/17/4/R177

\begin{abstract}
Controversy exists on the role of hyperoxia in major trauma with brain injury. Hyperoxia on arterial blood gas has been associated with acute lung injury and pulmonary complications, impacting clinical outcome. The hyperoxia could be reflective of the physiological interventions following major systemic trauma.

Despite the standard resuscitation of patients with acute traumatic brain injury, up to $60 \%$ demonstrate low brain oxygen upon admission to the ICU. While eubaric hyperoxia has been beneficial in experimental studies, clinical brain oxygen protocols incorporating intracranial pressure control, maintenance of cerebral perfusion pressure, and the effective use of fraction of inspired oxygen adjustments to maintain cerebral oxygenation levels $>20$ to $25 \mathrm{mmHg}$ have demonstrated mortality reductions and improved clinical outcomes. The risk of low brain oxygen is most acute in the first 24 to 48 hours after injury. The administration of a high fraction of inspired oxygen ( 0.6 to 1.0 ) in the emergency room may be justifiable until ICU admission for the placement of invasive neurocritical care monitoring systems. Thereafter, fraction of inspired oxygen levels need to be careful titrated to prevent low brain oxygen levels.
\end{abstract}

One of the major advantages of bureaucratic institutionalized national healthcare systems is the ability to analyze treatment paradigms implemented across a wide population, providing a comprehensive overview of clinical care with the view to improve quality and outcome. In a retrospective interrogation of a prospectively collected database, Raj and colleagues demonstrate that the presence of arterial hyperoxia within the first 24 hours is

Correspondence: narotam@mac.com

Union Hospital Neuroscience, 1530 N. 7th Street, suite 500, Terre Haute, IN 47807, USA not a predictive marker of neurological outcome in moderate to severe traumatic brain injury (TBI) [1].

The human has evolved into a complex adaptive system that is dynamic, exhibiting nonlinear relationships, and is acutely affected by many physiological systems [2]. Although trauma scoring systems (for example, injury severity score, revised trauma score and probability of survival) or physiological scoring methods (for example, Acute Physiology and Chronic Health Evaluation) employ a multitude of parameters, the use of a single physiological parameter - for example, arterial hyperoxia [1] - is not predictive for outcome. The hyperoxia detected could be reflective of the therapeutic intervention associated with major trauma, and the subsequent treatment and clinical course would vary after the initial arterial blood oxygen measurement since $<50 \%$ of patients underwent intracranial pressure monitoring [1]. Even when intracranial pressure monitoring is implemented, a high mortality is observed. Rockswold and colleagues reported a mortality of $42 \%$ in the control group for severe TBI, similar to the publication by Raj and colleagues $(39 \%)[1,3]$, but the addition of hyperoxia results in a significant relative risk reduction for mortality [3], similar to other published studies [4,5].

Early initiation of brain oxygen protocols - that is, intracranial pressure/cerebral perfusion pressure/partial pressure of brain tissue oxygen $\left(\mathrm{PbtO}_{2}\right)$ [5-7] and $\mathrm{PbtO}_{2}$ critical care guide $[4,8-10]$ - have shown mortality reductions $[4,5]$ and improved patient neurological outcome [4], in contrast to delayed implementation, which may not translate into outcome benefits [11]. The addition of oxygen as a therapeutic tool would necessitate multimodality invasive neurological monitoring in all patients with severe TBI since the fraction of inspired oxygen and airway pressures (that is, positive endexpiratory pressure or pressure support) would need to be carefully titrated against $\mathrm{PbtO}_{2}$ levels.

The deleterious effects of eubaric hyperoxia (that is, adult respiratory distress syndrome, atelectasis, 
ventilation/perfusion mismatch) have been postulated, which may be due to concomitant pulmonary contusion, aspiration or even high ventilator pressures [12], but have not been substantiated by clinical experience [3-5,9]. Indeed, eubaric hyperoxia - needed primarily in the first 48 hours [4] - immediately improves $\mathrm{PbtO}_{2}$, reducing lactate levels and infarct size, and exhibits neuroprotective properties $[13,14]$. High airway pressure of barotraumas, previously implicated in lung injury [12], has been refuted by Rockswold and colleagues who demonstrated the safety and efficacy of eubaric and hyperbaric oxygen therapy in the management of acute TBI in a randomized control study. Specifically, bronchial alveolar lavage revealed no differences in interleukin levels and, rather than toxicity, microdialysis data revealed the neuroprotective effects of oxygen in both the normal and the injured brain [3].

In conclusion, one has to differentiate between hyperoxia (detected in laboratory tests) with its potential association with clinical outcome, and the use of eubaric or hyperbaric oxygen as a therapeutic tool. In the former, a single episode of hyperoxia may have shown an association with mortality as reported in this study [1], but it would rarely prove causality. In the latter, the high therapy intensity level employed with brain oxygen protocols, of which eubaric hyperoxia is critical, requires invasive monitoring with careful goal-directed oxygen titration. The emerging clinical experience demonstrates that hyperoxia is safe and beneficial to the brain, and does not injure the lung as previously feared [3].

\section{Abbreviations}

$\mathrm{PbtO}_{2}$ : Partial pressure of brain tissue oxygen; TBI: Traumatic brain injury.

\section{Competing interests}

PKN served as a scientific advisor for Integra Neurosciences, Plainsboro, NJ, USA, who manufactured the neuromonitoring devices between 2001 and 2010.

Published: 16 Oct 2013

\section{References}

1. Raj R, Bendel S, Reinikainen M, Kivisaari R, Siironen J, Lang M, Skrifvars M: Hyperoxemia and long-term outcome after traumatic brain injury. Crit Care 2013, 17:R177.

2. Burggren WW, Monticino MG: Assessing physiological complexity. J Exp Biol 2005, 208:3221-3232.

3. Rockswold SB, Rockswold GL, Zaun DA, Liu J: A prospective, randomized phase II clinical trial to evaluate the effect of combined hyperbaric and normobaric hyperoxia on cerebral metabolism, intracranial pressure, oxygen toxicity, and clinical outcome in severe traumatic brain injury: clinical article. J Neurosurg 2013, 118:1317-1328.

4. Narotam PK, Morrison JF, Nathoo N: Brain tissue oxygen monitoring in traumatic brain injury and major trauma: outcome analysis of a brain tissue oxygen-directed therapy. J Neurosurg 2009, 111:672-682.

5. Stiefel MF, Spiotta A, Gracias VH, Garuffe AM, Guillamondegui O, MaloneyWilensky E, Bloom S, Grady MS, LeRoux PD: Reduced mortality rate in patients with severe traumatic brain injury treated with brain tissue oxygen monitoring. J Neurosurg 2005, 103:805-811.

6. Stiefel MF, Udoetuk JD, Spiotta AM, Gracias VH, Goldberg A, MaloneyWilensky E, Bloom S, Le Roux PD: Conventional neurocritical care and cerebral oxygenation after traumatic brain injury. J Neurosurg 2006, 105:568-575.

7. Spiotta AM, Stiefel MF, Gracias VH, Garuffe AM, Kofke WA, Maloney-Wilensky E, Troxel AB, Levine JM, Le Roux PD: Brain tissue oxygen-directed management and outcome in patients with severe traumatic brain injury. J Neurosurg 2010, 113:571-580.

8. Narotam PK, Burjonrappa SC, Raynor SC, Rao M, Taylon C: Cerebral oxygenation in major pediatric trauma: its relevance to trauma severity and outcome. J Pediatr Surg 2006, 41:505-513.

9. Narotam PK, Puri V, Roberts JM, Taylon C, Vora Y, Nathoo N: Management of hypertensive emergencies in acute brain disease: evaluation of the treatment effects of intravenous nicardipine on cerebral oxygenation. $J$ Neurosurg 2008, 109:1065-1074

10. Vath A, Meixensberger J, Dings J, Roosen K: Advanced neuromonitoring including cerebral tissue oxygenation and outcome after traumatic brain injury. Neurol Res 2001, 23:315-320.

11. Martini RP, Deem S, Yanez ND, Chesnut RM, Weiss NS, Daniel S, Souter M, Treggiari MM: Management guided by brain tissue oxygen monitoring and outcome following severe traumatic brain injury. J Neurosurg 2009, 111:644-649.

12. Carvalho CR, De Paula Pinto Schettino G, Maranhao B, Bethlem EP. Hyperoxia and lung disease. Curr Opin Pulmon Med 1998, 4:300-304.

13. Menzel M, Doppenberg EM, Zauner A, Soukup J, Reinert MM, Bullock R: Increased inspired oxygen concentration as a factor in improved brain tissue oxygenation and tissue lactate levels after severe human head injury. J Neurosurg 1999, 91:1-10.

14. Singhal AB, Dijkhuizen RM, Rosen BR, Lo EH: Normobaric hyperoxia reduces $M R I$ diffusion abnormalities and infarct size in experimental stroke. Neurology 2002, 58:945-952.

\section{$10.1186 / \mathrm{cc} 13065$}

Cite this article as: Narotam: Eubaric hyperoxia: controversies in the management of acute traumatic brain injury. Critical Care 2013, 17:197 